\title{
Human aqueous humor levels of transforming growth factor-ß32: Association with matrix metalloproteinases/tissue inhibitors of matrix metalloproteinases
}

\author{
YAN JIA $^{1,2^{*}}$, YU YUE $^{1 *}$, DAN-NING HU ${ }^{3}$, JI-LI CHEN ${ }^{4}$ and JI-BO ZHOU ${ }^{1}$ \\ ${ }^{1}$ Department of Ophthalmology, Shanghai Ninth People's Hospital, Shanghai Jiaotong University, \\ School of Medicine, Shanghai 200011; ${ }^{2}$ Department of Ophthalmology, Children's Hospital of Fudan University, \\ Shanghai Fudan University, School of Medicine, Shanghai 201102, P.R. China; ${ }^{3}$ Departments of Ophthalmology \\ and Pathology, New York Eye and Ear Infirmary of Mount Sinai, New York, NY 10003, USA; \\ ${ }^{4}$ Department of Ophthalmology, Shibei Hospital, Shanghai 200435, P.R. China
}

Received June 2, 2017; Accepted September 29, 2017

DOI: 10.3892/br.2017.1004

\begin{abstract}
The present study aims to investigate the association of transforming growth factor- $\beta 2$ (TGF- $\beta 2$ ) and matrix metalloproteinases (MMPs), MMP-2 and MMP-3, and tissue inhibitors of matrix metalloproteinases (TIMPs), TIMP-1, TIMP-2 and TIMP-3 in the aqueous humor of patients with high myopia or cataracts. The levels of TGF- $\beta 2$ and MMPs/TIMPs were measured with the Luminex xMAP Technology using commercially available Milliplex xMAP kits. The association between TGF- $\beta 2$ and MMPs/TIMPs levels was analyzed using the Spearman's correlation test. The levels of TGF- $\beta 2$ were identified to be positively correlated with the levels of TIMP-1 and TIMP-3 (TIMP-1: $\mathrm{r}=0.334 ; \mathrm{P}=0.007$; TIMP-3: $\mathrm{r}=0.309$; $\mathrm{P}=0.012$ ). The levels of MMP-2, MMP-3 and TIMP-2 did not significantly correlate with TGF- $\beta 2$ levels $(\mathrm{P}>0.05)$. A positive correlation was identified between TGF- $\beta 2$ and TIMPs in the aqueous humor of human eyes with elongated axial length. It appears that TGF- $\beta 2$ stimulates the expression of TIMPs as a compensatory reaction to the development of high myopia.
\end{abstract}

Correspondence to: Professor Ji-Bo Zhou, Department of Ophthalmology, Shanghai Ninth People's Hospital, Shanghai Jiaotong University, School of Medicine, 500 Quxi Road, Huangpu, Shanghai 200011, P.R. China

E-mail: zhoujibo1000@aliyun.com

Dr Ji-Li Chen, Department of Ophthalmology, Shibei Hospital, 4500 Gonghexin Road, Jing'an, Shanghai 200435, P.R. China

E-mail: corneachen@163.com

${ }^{*}$ Contributed equally

Key words: high myopia, aqueous humor, transforming growth factor- $\beta 2$, matrix metalloproteinases, tissue inhibitors of matrix metalloproteinases, correlation study

\section{Introduction}

Myopia is becoming more prevalent in China. High myopia has many serious complications that may lead to severe vision impairment. During the development of myopia, there is a loss of extracellular matrix (ECM), which may cause sclera remolding and axial elongation (1). Despite the changes in scleral ECM that occur during mammalian myopia development, there is relatively little understanding of the cellular and signaling factors that drive such changes. Increasing evidence has indicated that the retina and other relevant ocular tissues may synthesize and secrete transforming growth factor- $\beta 2$ (TGF- $\beta 2$ ) to regulate the remodeling of the sclera (2-5), which may result in myopia development. TGF- $\beta$ has been demonstrated in vitro to induce matrix metalloproteinases (MMPs) production from fibroblasts by interfering with the Smad and mitogen-activated protein kinases (MAPK) signaling pathways (6). MMPs are a family of enzymes that are capable of triggering the decomposition of scleral ECM components, the activities of which are regulated by physiological inhibitors, known as tissue inhibitors of matrix metalloproteinases (TIMPs) (7-13). TGF- $\beta 2$, MMPs and TIMPs are key in the progression of ECM degradation during the pathological processes of myopia (14-17). To the best of our knowledge, the correlation between TGF- $\beta 2$ and MMPs/ TIMPs in human aqueous humor in myopic patients has not previously been reported. Recently, TGF- $\beta 2$ and MMP/TIMP levels in the aqueous humor were evaluated in 65 patients with high myopia or cataract and it was identified that the TGF- $\beta 2$ and MMP/TIMP levels in the aqueous humor of patients with high myopia were significantly different from patients with cataract $(17,18)$. As a follow up study of our published studies $(17,18)$, the aim of the present study was to use the data $(17,18)$ to analyze the correlation between TGF- $\beta 2$ and MMP/TIMP levels in the aqueous humor from these patients.

\section{Materials and methods}

Patients and samples. The subjects and methods used for the measurement of multiple factors in the current study have been 
reported previously $(17,18)$. The previous studies included two groups of patients as follows: High myopia (35 cases) and cataract (30 cases). High myopia was defined as patients (with or without cataract) with refraction <-6 D (35 cases, 35 eyes). Cataract cases included cataract patients with a range of different refractive statuses; including emmetropia, hyperopia and myopia, with the exception of high myopia (30 cases, 30 eyes).

Specimens were obtained at the beginning of the clear lens extraction or cataract extraction surgery to avoid the breakdown of the blood-aqueous barrier associated with surgical manipulation. A 30-gauge needle attached to a tuberculin microsyringe was used to aspirate the aqueous humor from the central pupillary area without touching the iris, lens, or corneal endothelium with the needle to avoid trauma and the contamination of the aqueous humor specimens by various tissue components or blood. Specimens were stored immediately below $-80^{\circ} \mathrm{C}$ until analysis $(17,18)$.

All samples were assayed for total protein levels of TGF- $\beta 2$, MMP-1, -2, -3, TIMP-1, -2 , and -3 using a Luminex system (Luminex xMAP Technology, Bio-Rad Laboratories, Inc., Hercules, CA, USA) and commercially available Milliplex xMAP kits (TGFB-64K-03, HMMP2MAG-55K-02, HMMP1M AG-55K-01, HTMP2MAG-54K-03; EMD Millipore, Billerica, MA, USA) (17-20).

All patients signed informed consent and the study was approved by the Institutional Review Board at the Shanghai Ninth People's Hospital, Shanghai Jiaotong University School of Medicine (Shanghai, China) (17,18).

Analysis of the association between TGF- $\beta 2$ and TIMPs. The association between the levels of TGF- $\beta 2$ and various MMPs/TIMPs (MMP-2, MMP-3, TIMP-1, TIMP-2 and TIMP-3) was analyzed separately by evaluating the significance of the correlation coefficient between various groups.

Statistical analysis. The original data were not normally distributed according to the Kolmogorov-Smirnov test. Therefore, the results were expressed as medians and ranges (25th and 75th percentiles) using continuous variables that are not normally distributed, such as the levels of TGF- $\beta 2$ and TIMPs, or as a mean (standard deviation) for normally distributed continuous variables, such as age. The association between TGF- $\beta 2$ and TIMPs was analyzed using Spearman's correlation test. SPSS 22.0 software for Windows (IBM Corp., Armonk, NY, USA) was used to perform these analyses. A two-tailed $\mathrm{P}<0.05$ was considered to indicate a statistically significant difference.

\section{Results}

Analysis of the levels of MMPs, TIMPs and TGF- $\beta 2$. Briefly, the average age of the 65 patients was $67.0 \pm 11.7$ years, comprising of 29 males and 36 females (17). Among the 65 subjects, 30 eyes had cataracts and 35 eyes were highly myopic (all in the stationary stage). The results of the levels of TGF- $\beta 2$ and TIMPs were published in our previous papers $(17,18)$, which revealed that MMP-1 was not detected and TGF- $\beta 2$, MMP-2, MMP-3, TIMP-1, TIMP-2 and TIMP-3 were detected in the aqueous humor. The levels of TGF- $\beta 2$, MMP-2, TIMP-1,

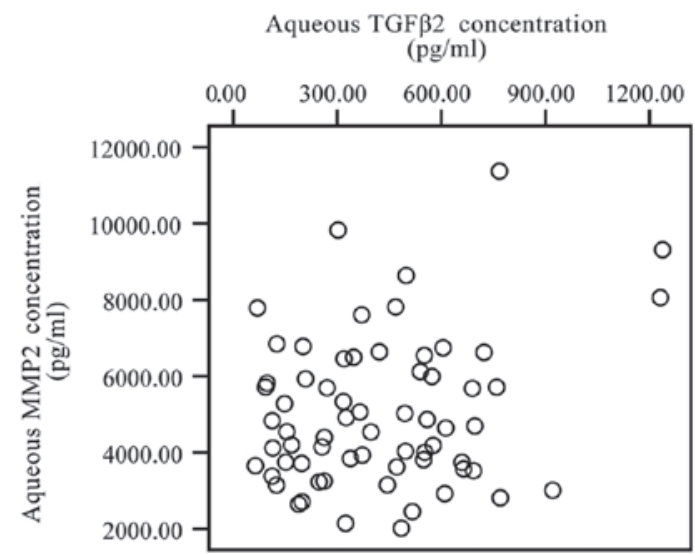

Figure 1. Correlation between aqueous TGF- $\beta 2$ and MMP-2 levels. TGF- $\beta 2$ and MMP-2 levels in the aqueous humor from 65 patients with myopia or cataract during cataract or clear lens extraction surgery were measured with Luminex xMAP Technology using commercially available Milliplex xMAP kits. Spearman's correlation test demonstrated that TGF- $\beta 2$ was not correlated with MMP-2 ( $\mathrm{P}>0.05)$. TGF- $\beta 2$, transforming growth factor- $\beta 2$; MMP-2, matrix metalloproteinase-2

TIMP-2, TIMP-3 in the high myopia group were significantly higher than those in the cataract eyes group, while MMP-3 levels in the high myopia group were not statistically higher than that in the cataract eyes group.

Correlation of TGF- $\beta 2$ with MMPs. In the present study, the correlation between the levels of TGF- $\beta 2$ and different MMPs/TIMPs in the aqueous humor specimens was analyzed by Spearman's correlation test. The TGF- $\beta 2$ level was not identified to be significantly correlated with the MMP-2 level $(\mathrm{P}>0.05)$, although the levels of the two increased in the aqueous humor (Fig. 1). Furthermore, the levels of TGF- $\beta 2$ were also not significantly correlated with the levels of MMP-3 (P>0.05; Fig. 2).

Correlation of TGF- $\beta 2$ with TIMPs. A significantly positive correlation was identified between the levels of TGF- $\beta 2$ and TIMP-1 ( $\mathrm{r}=0.334, \mathrm{P}=0.007$; Fig. 3 ), and with TGF- $\beta 2$ and TIMP-3 ( $r=0.309, \mathrm{P}=0.012$; Fig. 4). However, no significant correlation was observed between the levels of TGF- $\beta 2$ and TIMP-2 (P>0.05; Fig. 5).

\section{Discussion}

In the current study, the associations between TGF- $\beta 2$ and MMPs/TIMPs in the aqueous humor of myopia and cataract patients were analyzed, with the aim of highlighting the role of TGF- $\beta 2$ and MMPs/TIMPs in the development of myopia.

TGF- $\beta 2$ is an important factor in the modulation of growth and development of the eyeball (21). In four-week-old guinea pigs, it was demonstrated that the retinal levels of the TGF- $\beta 2$ protein are highly correlated with ocular refraction and axial length (22). TGF- $\beta 2$ is a key factor in the progression of myopia development and axial elongation; however, reports of its expression in experimental myopia have been controversial as animal studies have demonstrated increases and decreases (22-26). It appears that the changes in TGF- $\beta 2$ expression during the development of myopia are species- and tissue-specific $(22-24,25,27)$. Our 


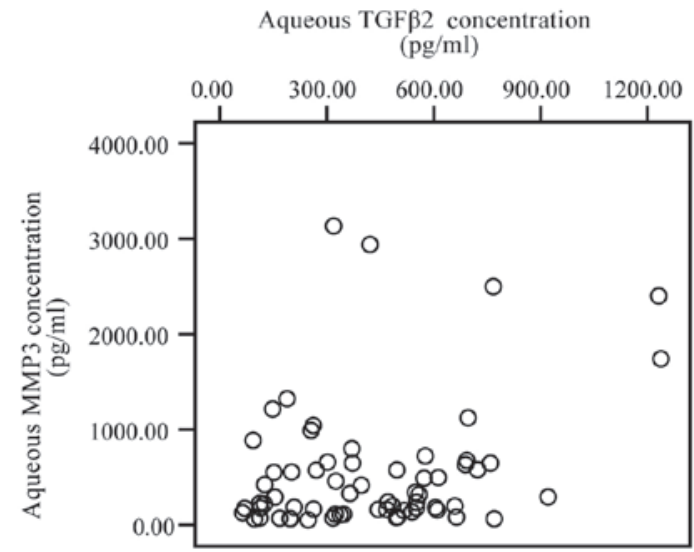

Figure 2. Correlation between aqueous TGF- $\beta 2$ and MMP-3 levels. TGF- $\beta 2$ and MMP-3 levels in the aqueous humor from 65 patients with myopia or cataract during cataract or clear lens extraction surgery were measured with the Luminex xMAP Technology using commercially available Milliplex xMAP kits. Spearman's correlation test demonstrated that TGF- $\beta 2$ was not correlated with MMP-3 ( $\mathrm{P}>0.05)$. TGF- $\beta 2$, transforming growth factor- $\beta 2$; MMP-2, matrix metalloproteinase-2.

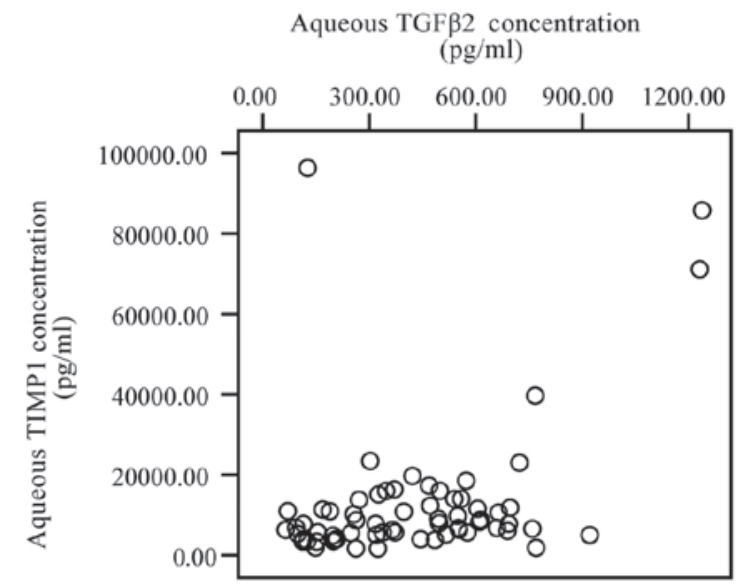

Figure 3. Correlation between aqueous TGF- $\beta 2$ and TIMP-1 levels. TGF- $\beta 2$ and TIMP-1 levels in the aqueous humor from 65 patients with myopia or cataract during cataract or clear lens extraction surgery were measured with the Luminex xMAP Technology using commercially available Milliplex $x$ MAP kits. Spearman's correlation test demonstrated that TGF- $\beta 2$ was positively correlated with TIMP-1 ( $\mathrm{r}=0.334 ; \mathrm{P}=0.007)$. TGF- $\beta 2$, transforming growth factor- $\beta 2$; TIMP-1, tissue inhibitors of matrix metalloproteinase-1.

previous study (18) and the study by Zhuang et al (28) found that TGF- $\beta 2$ levels were increased in the aqueous or vitreous humor in stationary high myopia patients with axial elongation $(18,28)$.

TIMPs are a group of endogenous specific inhibitors of the activity of various MMPs, and the balance between MMPs/TIMPs regulates ECM turnover and remodeling during normal development and pathogenesis (11). Animal studies have revealed that the levels of MMPs increased during the development period of myopia $(29,30)$. Our previous study (17) and the study by Zhuang et al (28) identified that aqueous MMP-2 and -3 levels increased in ocular specimens during the stationary stage of high myopia patients $(17,28)$. TIMPs inhibit the degradation of ECM, which is caused by MMPs. Therefore, it is expected that during various physiological or pathological processes that involve the degradation of the

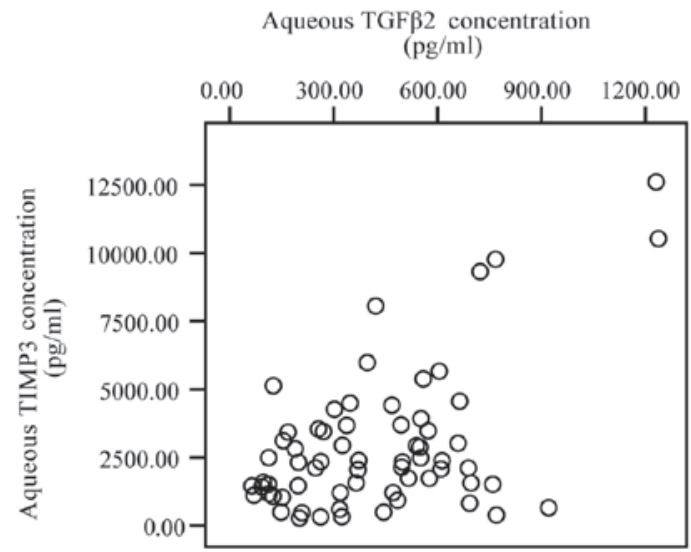

Figure 4. Correlation between aqueous TGF- $\beta 2$ and TIMP-3 levels. TGF- $\beta 2$ and TIMP-3 levels in the aqueous humor from 65 patients with myopia or cataract during cataract or clear lens extraction surgery were measured with the Luminex xMAP Technology using commercially available Milliplex xMAP kits. Spearman's correlation test showed that TGF- $\beta 2$ was positively correlated with TIMP-3 ( $\mathrm{r}=0.309 ; \mathrm{P}=0.012)$. TGF- $\beta 2$, transforming growth factor- $\beta 2$; TIMP-3, tissue inhibitors of matrix metalloproteinase-3.

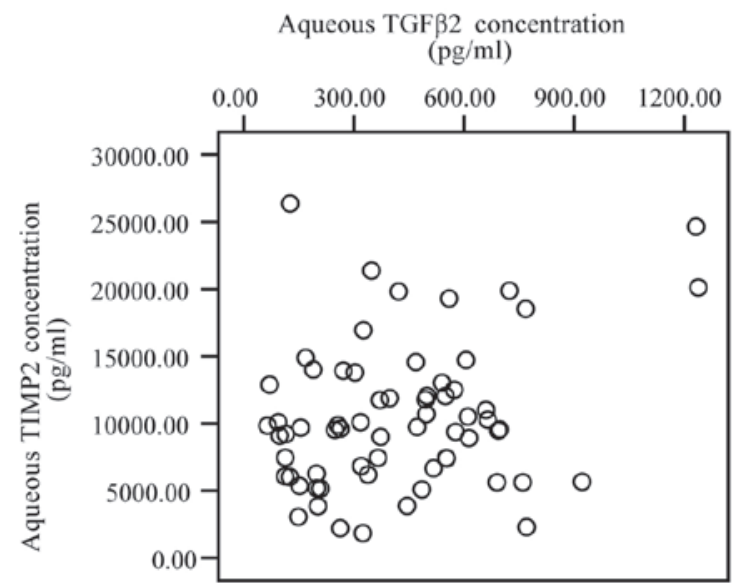

Figure 5. Correlation between aqueous TGF- $\beta 2$ and TIMP-2 levels. TGF- $\beta 2$ and TIMP-2 levels in the aqueous humor from 65 patients with myopia or cataract during cataract or clear lens extraction surgery were measured with the Luminex xMAP Technology using commercially available Milliplex xMAP kits. Spearman's correlation test demonstrated that TGF- $\beta 2$ was not correlated with TIMP-2 ( $\mathrm{P}>0.05)$. TGF- $\beta 2$, transforming growth factor- $\beta 2$; TIMP-2, tissue inhibitors of matrix metalloproteinase-2.

ECM, TIMP levels decrease and are associated with increased levels of MMPs; these changes lead to degradation of the ECM (8,10-12). However, under certain circumstances the levels of TIMPs do not decrease, they increase (8,10-13,31-45). These contradictory changes of TIMP have been explained by the homeostasis hypothesis, that is, the elevation of TIMP levels reflects a cellular compensatory reaction to counteract and limit the intensive degradation of ECM by MMPs. In this case, the TIMP expression levels should increase rather than decrease $(11-13,40,41,46,47)$.

In animal studies of myopia, the changes of TIMP levels during the development period of myopia are complicated; it has been reported that the levels of TIMP mRNA in the scleral increase $(14,48)$, decrease $(49,50)$ or do not change significantly $(49,50)$. During the recovery stage of experimental 
myopia, the MMP-2 levels invariably decrease, and the TIMP levels usually increase $(29,30,50,51)$.

Our previous studies revealed that the levels of TIMPs in the aqueous humor increased during the stationary stage of high myopia patients (17). This may be explained by the homeostasis hypothesis; the elevation in TIMP levels reflects a cellular compensatory reaction to counteract the degradation of ECM by MMPs.

Little is known regarding the molecular mechanism of this compensatory response of increased levels of TIMPs in myopia. The present study has demonstrated that the increase of TIMP-1 and TIMP-3 in the aqueous humor of high myopia patients was positively correlated with the increase of TGF- $\beta 2$ levels, indicating that TGF- $\beta 2$ may be the molecule that causes the increase in TIMP expression levels in high myopia. This is consistent with previous reports demonstrating that TGF- $\beta 2$ increased the levels of TIMP-1 in human RPE cells (52), and the upregulation of TIMP by TGF- $\beta$ s in human, rat or bovine chondrocytes and fibroblasts (53-58).

The signaling pathways of TGF- $\beta$-induced TIMP expression in myopia have not been investigated systematically; however, they has been evaluated in human and experimental animal fibroblasts and chondrocytes $(53,54,59)$.

Morris et al (59) demonstrated that TGF- $\beta$ increased the levels of the TIMP-3 protein in human cartilage, but did not significantly affect the expression levels of TIMP-3 mRNA (59). Wang et al (53) observed that TGF- $\beta$ induces TIMP-3 expression in rat chondrocytes via activation of the extracellular signal-regulated kinase (ERK)1/2 and Smad2/3 signaling pathways. Leivonen et al (54) identified that TGF- $\beta$ induced TIMP-3 mRNA expression in mouse and human fibroblasts. This effect was abolished by the inhibition of ERK1/2 activation and p38 mitogen-activated protein kinase (p38 MAPK), indicating that ERK1/2 and p38 MAPK mediate the effect of TGF- $\beta$ on TIMP-3 expression levels. Furthermore, Smad3 co-operated with p38 MAPK and ERK1/2 in the induction of TIMP-3 expression. The study demonstrated that TGF- $\beta$ induces TIMP-3 expression via a complex interplay between Smad3, p38, and ERK1/2 signaling (54).

The present analysis revealed that the levels of TGF- $\beta 2$ were positively correlated with the levels of TIMP-1 and TIMP-3, but were not associated with the levels of TIMP-2. This may be relevant to the differenteffects of various TIMPs on the expression levels of MMP; TIMP-1 and -3 are inhibitors of various MMPs. TIMP-2 is an inhibitor of MMPs, as well as an activator for pro-MMP-2. Furthermore, TIMP-2 binds to latent MMP-2 and MT1-MMP at the cell surface, resulting in proteolytic activation of the latent MMP-2 by adjacent MT1-MMP (7-9,11). It has been reported that at high concentrations, TIMP-2 causes inhibition; however, at low concentrations it increases the activities of MMP-2 $(8,11)$. This may provide an explanation for the different associations between TGF- $\beta$ and various TIMPs.

It has been reported that TGF- $\beta$ s may influence the expression level of MMPs (6). However, in the present study, the levels of MMPs in the aqueous humor in cataract or high myopia eyes were not identified to be correlated with TGF- $\beta 2$ levels. Therefore, the results of the present analysis indicate that in human high myopia, the effects of TGF- $\beta 2$ on the pathogenesis of myopia may be via the modulation of TIMP expression levels rather than by MMP expression levels.
However, the present study was based on the analysis of factors in the aqueous humor during the stationary stage of myopia, therefore, the results should be interpreted cautiously.

In conclusion, the present analysis has revealed that an increase in the levels of TIMPs in the aqueous humor in the stationary stage of human high myopia patients was positively correlated with the increase in TGF- $\beta 2$ levels. The elevation of TIMP expression levels most likely reflects a cellular compensatory reaction to counteract and limit the intense degradation of the ECM by MMPs. TGF- $\beta 2$ is possibly one of the molecules that is involved in the modulation of this process. However, the cause-effect association between the increase in TGF- $\beta$ and TIMP levels in the development of myopia and its mechanism requires further investigation.

\section{Acknowledgements}

The current study was supported by the National Nature Science Foundation of China (grant no. 81371050) and the Shanghai Municipal Commission of Health and Family Planning Fund (grant no. 201440354).

\section{References}

1. Chen BY, Wang CY, Chen WY and Ma JX: Altered TGF- $\beta 2$ and bFGF expression in scleral desmocytes from an experimentallyinduced myopia guinea pig model. Graefes Arch Clin Exp Ophthalmol 251: 1133-1144, 2013.

2. Hodos W and Kuenzel WJ: Retinal-image degradation produces ocular enlargement in chicks. Invest Ophthalmol Vis Sci 25: 652-659, 1984.

3. Nagineni CN, Cherukuri KS, Kutty V, Detrick B and Hooks JJ: Interferonamma differentially regulates TGF- $\beta 1$ and TGF- $\beta 2$ expression in human retinal pigment epithelial cells through JAK-STAT pathway. J Cell Physiol 210: 192-200, 2007.

4. Seko Y, Tanaka Y and Tokoro T: Scleral cell growth is influenced by retinal pigment epithelium in vitro. Graefes Arch Clin Exp Ophthalmol 232: 545-552, 1994.

5. Troilo D, Nickla DL, Mertz JR and Summers Rada JA: Change in the synthesis rates of ocular retinoic acid and scleral glycosaminoglycan during experimentally altered eye growth in marmosets. Invest Ophthalmol Vis Sci 47: 1768-1777, 2006.

6. Asano K, Shikama Y, Shoji N, Hirano K, Suzaki H and Nakajima H: Tiotropium bromide inhibits TGF- $\beta$-induced MMP production from lung fibroblasts by interfering with smad and MAPK pathways in vitro. Int J Chron Obstruct Pulmon Dis 5: 277-286, 2010.

7. Murphy $\mathrm{G}$ and Nagase $\mathrm{H}$ : Progress in matrix metalloproteinase research. Mol Aspects Med 29: 290-308, 2008.

8. Kahari V and Saarialho-Kere U: Matrix metalloproteinases and their inhibitors in tumour growth and invasion. Ann Med 31: 34-45, 1999.

9. Brew K, Dinakarpandian D and Nagase H: Tissue inhibitors of metalloproteinases: evolution, structure and function. Biochim Biophys Acta 1477: 267-283, 2000.

10. Groblewska M, Siewko M, Mroczko B and Szmitkowski M: The role of matrix metalloproteinases (MMPs) and their inhibitors (TIMPs) in the development of esophageal cancer. Folia Histochem Cytobiol 50: 12-19, 2012.

11. Chirco R, Liu XW, Jung KK and Kim HR: Novel functions of TIMPs in cell signaling. Cancer Metastasis Rev 25: 99-113, 2006.

12. Egeblad M and Werb Z: New functions for the matrix metalloproteinases in cancer progression. Nat Rev Cancer 2: 161-174, 2002.

13. Sternlicht MD and Werb Z: How matrix metalloproteinases regulate cell behavior. Annu Rev Cell Dev Biol 17: 463-516, 2001.

14. McBrien NA and Gentle A: Role of the sclera in the development and pathological complications of myopia. Prog Retin Eye Res 22: 307-338, 2003.

15. Gao H, Frost MR, Siegwart JT Jr and Norton TT: Patterns of mRNA and protein expression during minus-lens compensation and recovery in tree shrew sclera. Mol Vis 17: 903-919, 2011. 
16. Shelton L and Rada JS: Effects of cyclic mechanical stretch on extracellular matrix synthesis by human scleral fibroblasts. Exp Eye Res 84: 314-322, 2007.

17. Jia Y, Hu DN, Zhu D, Zhang L, Gu P, Fan X and Zhou J: MMP-2, MMP-3, TIMP-1, TIMP-2, and TIMP-3 protein levels in human aqueous humor: relationship with axial length. Invest Ophthalmol Vis Sci 55: 3922-3928, 2014.

18. Jia Y, Hu DN and Zhou J: Human aqueous humor levels of TGF$\beta 2$ : relationship with axial length. Biomed Res Int 2014: 258591, 2014.

19. Manise M, Holtappels G, Van Crombruggen K, Schleich F, Bachert C and Louis R: Sputum IgE and cytokines in asthma: relationship with sputum cellular profile. PLoS One 8: e58388, 2013.

20. Codices V, Martins C, Novo C, de Sousa B, Lopes Â, Borrego M and Matos O: Dynamics of cytokines and immunoglobulins serum profiles in primary and secondary Cryptosporidium parvum infection: usefulness of Luminext xMAP technology. Exp Parasitol 133: 106-113, 2013.

21. Bajracharya D, Shrestha B, Kamath A, Menon A and Radhakrishnan R: Immunohistochemical correlation of matrix metalloproteinase-2 and tissue inhibitors of metalloproteinase-2 in tobacco associated epithelial dysplasia. Dis Marker 2014: 197813,2014

22. Seko Y, Shimokawa $H$ and Tokoro T: Expression of bFGF and TGF-beta 2 in experimental myopia in chicks. Invest Ophthalmol Vis Sci 36: 1183-1187, 1995.

23. Honda S, Fujii S, Sekiya Y and Yamamoto M: Retinal control on the axial length mediated by transforming growth factor-beta in chick eye. Invest Ophthalmol Vis Sci 37: 2519-2526 1996.

24. McBrien NA: Regulation of scleral metabolism in myopia and the role of transforming growth factor-beta. Exp Eye Res 114: 128-140, 2013

25. Jobling AI, Nguyen M, Gentle A and McBrien NA: Isoformspecific changes in scleral transforming growth factor- $\beta$ expression and the regulation of collagen synthesis during myopia progression. J Biol Chem 279: 18121-18126 2004

26. Estella C, Herrer I, Atkinson SP, Quiñonero A, Martínez S, Pellicer A and Simón C: Inhibition of histone deacetylase activity in human endometrial stromal cells promotes extracellular matrix remodelling and limits embryo invasion. PLoS One 7: e30508, 2012.

27. Jobling AI, Wan R, Gentle A, Bui BV and McBrien NA: Retinal and choroidal TGF- $\beta$ in the tree shrew model of myopia: isoform expression, activation and effects on function. Exp Eye Res 88 458-466, 2009

28. Zhuang H, Zhang R, Shu Q, Jiang R, Chang Q, Huang X, Jiang C and Xu G: Changes of TGF- $\beta 2$, MMP-2, and TIMP-2 levels in the vitreous of patients with high myopia. Graefes Arch Clin Exp Ophthalmol 252: 1763-1767, 2014

29. Guggenheim JA and McBrien NA: Form-deprivation myopia induces activation of scleral matrix metalloproteinase-2 in tree shrew. Invest Ophthalmol Vis Sci 37: 1380-1395, 1996.

30. Siegwart JT Jr and Norton TT: Selective regulation of MMP and TIMP mRNA levels in tree shrew sclera during minus lens compensation and recovery. Invest Ophthalmol Vis Sci 46: 3484-3492, 2005.

31. Chavey C, Mari B, Monthouel MN, Bonnafous S, Anglard P, Van Obberghen E and Tartare-Deckert S: Matrix metalloproteinases are differentially expressed in adipose tissue during obesity and modulate adipocyte differentiation. J Biol Chem 278: $11888-11896,2003$.

32. Limaye AM, Desai KV, Chavalmane AK and Kondaiah P: Regulation of mRNAs encoding MMP-9 and MMP-2, and their inhibitors TIMP-1 and TIMP-2 by androgens in the rat ventral prostate. Mol Cell Endocrinol 294: 10-18, 2008.

33. Ma DH, Chen JK, Kim WS, Hao YX, Wu HC, Tsai RJ, Hwang DG and Zhang F: Expression of matrix metalloproteinases 2 and 9 and tissue inhibitors of metalloproteinase 1 and 2 in inflammation-induced corneal neovascularization. Ophthalmic Res 33: 353-362, 2001.

34. Webb KE, Henney AM, Anglin S, Humphries SE and McEwan JR: Expression of matrix metalloproteinases and their inhibitor TIMP-1 in the rat carotid artery after balloon injury. Arterioscler Thromb Vasc Biol 17: 1837-1844, 1997.

35. Lakatos G, Hritz I, Varga MZ, Juhász M, Miheller P, Cierny G Tulassay $\mathrm{Z}$ and Herszényi L: The impact of matrix metalloproteinases and their tissue inhibitors in inflammatory bowel diseases. Dig Dis 30: 289-295, 2012.
36. Gomez DE, De Lorenzo MS, Alonso DF and Andrade ZA Expression of metalloproteinases (MMP-1, MMP-2, and MMP-9) and their inhibitors (TIMP-1 and TIMP-2) in schistosomal portal fibrosis. Am J Trop Med Hyg 61: 9-13, 1999.

37. Knittel T, Mehde M, Grundmann A, Saile B, Scharf JG and Ramadori G: Expression of matrix metalloproteinases and their inhibitors during hepatic tissue repair in the rat. Histochem Cell Biol 113: 443-453, 2000.

38. Figueira RC, Gomes LR, Neto JS, Silva FC, Silva ID and Sogayar MC: Correlation between MMPs and their inhibitors in breast cancer tumor tissue specimens and in cell lines with different metastatic potential. BMC Cancer 9: 20, 2009.

39. Gress TM, Müller-Pillasch F, Lerch MM, Friess H, Buchler M and Adler G: Expression and in-situ localization of genes coding for extracellular matrix proteins and extracellular matrix degrading proteases in pancreatic cancer. Int J Cancer 62: 407-413, 1995.

40. Poruk KE, Firpo MA, Scaife CL, Adler DG, Emerson LL, Boucher KM and Mulvihill SJ: Serum osteopontin and tissue inhibitor of metalloproteinase 1 as diagnostic and prognostic biomarkers for pancreatic adenocarcinoma. Pancreas 42: 193-197, 2013.

41. Gardner J and Ghorpade A: Tissue inhibitor of metalloproteinase (TIMP)-1: the TIMPed balance of matrix metalloproteinases in the central nervous system. J Neurosci Res 74: 801-806, 2003.

42. Singh RD, Haridas N, Patel JB, Shah FD, Shukla SN, Shah PM and Patel PS: Matrix metalloproteinases and their inhibitors: correlation with invasion and metastasis in oral cancer. Indian J Clin Biochem 25: 250-259, 2010.

43. Wallard MJ, Pennington CJ, Veerakumarasivam A, Burtt G, Mills IG, Warren A, Leung HY, Murphy G, Edwards DR, Neal DE and Kelly JD: Comprehensive profiling and localisation of the matrix metalloproteinases in urothelial carcinoma. Br J Cancer 94: 569-577, 2006.

44. Kossakowska AE, Huchcroft SA, Urbanski SJ and Edwards DR: Comparative analysis of the expression patterns of metalloproteinases and their inhibitors in breast neoplasia, sporadic colorectal neoplasia, pulmonary carcinomas and malignant non-Hodgkin's lymphomas in humans. Br J Cancer 73: 1401-1408, 1996.

45. Ma J, Wang J, Fan W, Pu X, Zhang D, Fan C, Xiong L, Zhu H, $\mathrm{Xu}$ N, Chen R and Liu S: Upregulated TIMP-1 correlates with poor prognosis of laryngeal squamous cell carcinoma. Int J Clin Exp Pathol 7: 246-254, 2013.

46. Ylisirniö S, Höyhtyä M and Turpeenniemi-Hujanen T: Serum matrix metalloproteinases $-2,-9$ and tissue inhibitors of metalloproteinases $-1,-2$ in lung cancer - TIMP-1 as a prognostic marker. Anticancer Res 20: 1311-1316, 2000.

47. Moore CS and Crocker SJ: An alternate perspective on the roles of TIMPs and MMPs in pathology. Am J Pathol 180: 12-16, 2012.

48. McBrien NA, Cornell LM and Gentle A: Structural and ultrastructural changes to the sclera in a mammalian model of high myopia. Invest Ophthalmol Vis Sci 42: 2179-2187, 2001.

49. Rada JA and Brenza HL: Increased latent gelatinase activity in the sclera of visually deprived chicks. Invest Ophthalmol Vis Sci 36: $1555-1565,1995$.

50. Rada JA, Perry CA, Slover ML and Achen VR: Gelatinase A and TIMP-2 expression in the fibrous sclera of myopic and recovering chick eyes. Invest Ophthalmol Vis Sci 40: 3091-3099, 1999.

51. Schippert R, Brand C, Schaeffel F and Feldkaemper MP: Changes in scleral $M M P-2, T I M P-2$ and $T G F \beta-2$ mRNA expression after imposed myopic and hyperopic defocus in chickens. Exp Eye Res 82: 710-719, 2006.

52. Eichler W, Friedrichs U, Thies A, Tratz C and Wiedemann P: Modulation of matrix metalloproteinase and TIMP-1 expression by cytokines in human RPE cells. Invest Ophthalmol Vis Sci 43: 2767-2773, 2002

53. Wang X, Zhu Y, Tao H, Jin C, Liu Y, Lu X, Hu X and Fan C: Interaction of ERK1/2 and $\operatorname{Smad} 2 / 3$ signaling pathways in TGF- $\beta 1$-induced TIMP-3 expression in rat chondrocytes. Arch Biochem Biophys 564: 229-236, 2014.

54. Leivonen SK, Lazaridis K, Decock J, Chantry A, Edwards DR and Kähäri VM: TGF- $\beta$-elicited induction of tissue inhibitor of metalloproteinases (TIMP)-3 expression in fibroblasts involves complex interplay between Smad3, p38a, and ERK1/2. PLoS One 8: e57474, 2013

55. Narcisi R, Quarto R, Ulivi V, Muraglia A, Molfetta L and Giannoni P: TGF $\beta-1$ administration during ex vivo expansion of human articular chondrocytes in a serum-free medium redirects the cell phenotype toward hypertrophy. J Cell Physiol 227: 3282-3290, 2012 . 
56. Luna J, Masamunt MC, Llach J, Delgado S and Sans M: Palm oil tocotrienol rich fraction reduces extracellular matrix production by inhibiting transforming growth factor- $\beta 1$ in human intestinal fibroblasts. Clin Nutr 30: 858-864, 2011.

57. Todorova L, Gürcan E, Westergren-Thorsson G and Miller-Larsson A: Budesonide/formoterol effects on metalloproteolytic balance in TGF $\beta$-activated human lung fibroblasts. Respir Med 103: 1755-1763, 2009.
58. Su S, Grover J, Roughley PJ, DiBattista JA, Martel-Pelletier J, Pelletier JP and Zafarullah M: Expression of the tissue inhibitor of metalloproteinases (TIMP) gene family in normal and osteoarthritic joints. Rheumatol Int 18: 183-191, 1999.

59. Morris KJ, Cs-Szabo G and Cole AA: Characterization of TIMP-3 in human articular talar cartilage. Connect Tissue Res 51: 478-490, 2010. 